\title{
Surface Stability of SU-8 Film for Accurate Biopotential Detection
}

\author{
Yuta Noguchi and Akira Kawai* \\ Department of Electrical Engineering, Nagaoka University of Technology \\ 1603-1 Kamitomioka, Nagaoka, Niigata 940-2188, Japan \\ *E-mail: kawai@nagaokaut.ac.jp
}

\begin{abstract}
Biopotential is important and sensitive information in order to monitor and control growth condition for living cells. For detecting biopotential change accurately, a stable biocompatible polymer film is required. In this study, a stable surface of a SU-8 film is characterized, and it is possible for applying to a cover material of electrode surface or an element of a biological implanted device. Surface potential $\mathrm{V}_{\mathrm{SU}-8}$ of a SU-8 film is measured by making a metallic electrode contact. As a standard equilibrium, $\mathrm{V}_{\mathrm{SU}-8}$ indicates exponential decreasing to reach at $+21 \mathrm{mV}$. Biopotential $\mathrm{V}_{\text {bio }}$ of plant cells indicates large potential change for 10 to $42 \mathrm{mV}$ range. This potential change means an individualistic signal of living cells. By combination of a SU-8 film and living cells, it is capable of obtaining accurate and effective data.
\end{abstract}

Keywords: SU-8 resist, plant cells, surface potential, biopotential, biocompatible material

\section{Introduction}

Biopotential is one electrical signal due to living cells. It can indicate sensitive information as related to living cells. In general, it is known that biopotential controls growth condition of cells. In order to analyze this field, a stable standard material is required to detect accurate biopotential change, such as a biocompatible polymer film.

Biocompatible materials have been focused and investigated extensively in various basic bioscience and engineering fields. In particular, polymer materials, such as polydimethylsiloxane (PDMS) and polytetrafluoroethylene (PTFE), have been yielded in practical applications, e.g., an artificial blood vessel, a cell culture substratum $[1,2]$. With regard to biomaterial, it is critical to have no interaction with a living tissue by contacting a biocompatible material. Interface characterization of a biomaterial has often discussed in terms of surface bonding state and protein adsorption capacity [3,4].

In this study, we focus on a SU-8 film which is epoxy-based negative photoresist as an interface material. In general, a monomer of SU-8 resist has eight epoxy functionalities; high degree of cross-linking after UV exposure can be obtained [5]. Therefore, a SU-8 film is stable in terms of mechanical and chemical interaction. Moreover, SU-8 has recognized as a candidate of biocompatible matrial by the Food and Drug Agency (FDA) of the United States [6]. In fact, a drug delivery MEMS (MicroElectroMechanical System) device, a microfluidic device and a probe for neuronal recording applications by SU-8 resist were reported [7-9].

The aim of this study is to characterize a stable surface of a SU-8 film in terms of surface electrical potential. In order to measure $\mathrm{V}_{\mathrm{SU}-8}$ as a surface electrical potential of a SU-8 film, a pair of tungsten needles is used. As a standard equilibrium, $\mathrm{V}_{\mathrm{SU}-8}$ indicates exponential decreasing, and its value reaches to $+22 \mathrm{mV}$. Then, $\mathrm{V}_{\text {bio }}$ as biopotential of plant cells is also measured by using the measurement system. The value of $\mathrm{V}_{\text {bio }}$ shows large potential change for 10 to $42 \mathrm{mV}$ range just after making a metallic electrode contact. This potential change should indicate an individualistic signal of living cells. In order to evaluate 
quantitatively, potentials both $\mathrm{V}_{\mathrm{SU}-8}$ and $\mathrm{V}_{\text {bio }}$ are fitted by an exponential function, and time constant $\tau$ is obtained from fitting parameters. Average of $\tau$ for $\mathrm{V}_{\mathrm{SU}-8}$ is $41 \mathrm{~s}$, however $\tau$ of $\mathrm{V}_{\text {bio }}$ changed randomly. According to compare $\mathrm{V}_{\mathrm{SU}-8}$ with $\mathrm{V}_{\text {bio }}$, a SU-8 film is capable to use as a standard film of surface potential analysis. A SU-8 film is possible for applying to a cover material of electrodes surface or an element of a biological implanted device.

\section{Experiment}

\subsection{Sample Preparation}

A double SU-8 layer structure for experimental sample was prepared in order to form a flat and low detect surfaces. Figure 1 shows a sample fabrication process. First, a glass plate (Matsunami Glass, S1111, 0.9mm thickness) was sawn by $26 \mathrm{~mm} \times 26 \mathrm{~mm}$ square. Then the glass was ultrasonic cleaned by dipping into acetone, ethanol and deionized water for $5 \mathrm{~min}$ respectively. Then, the SU-8 3005 photoresist liquid was dropped on the glass surface. The kinetic viscosity of the SU-8 liquid was $65 \mathrm{~mm}^{2} / \mathrm{s}$ according to SU-8 3000 series data sheet [10]. The spin rate was ramped in two steps up to $3000 \mathrm{rpm}$. Prebaking was carried out for $5 \mathrm{~min}$ at $95^{\circ} \mathrm{C}$ on a hotplate. Then, the glass was cooled down to room temperature. Then, whole area of the SU-8 film was exposed to $365 \mathrm{~nm}$ UV light at $6.0 \mathrm{~mJ} / \mathrm{cm}^{2}$ for $8 \mathrm{~s}$ utilizing a UV spot light system (Yamashita denso, Hypercure-200). After the exposure, the SU-8 film was cross-linked by performing a two-step post exposure bake (PEB) process on a $65^{\circ} \mathrm{C}$ hot plate for $1 \mathrm{~min}$ and for $4 \mathrm{~min}$ at $95^{\circ} \mathrm{C}$. The $\mathrm{SU}-8$ film was soaked in the SU-8 developer for $5 \mathrm{~min}$ in similar to the standard SU-8 lithography process. After soaking, hardbaking was carried out at $200^{\circ} \mathrm{C}$ for $60 \mathrm{~s}$. Then another SU-8 film was formed on the bottom SU-8 film with the same procedure parameters.

As shown in Fig.2a, pothos (Epipremnum aureum), a kind of foliage plants, was employed as a living tissue because pothos is easy to daily cultivation. The pothos cells were prepared as follows: a leaf of pothos was cut then stored under ambient conditions for $1 \mathrm{~h}$ before the measurement. Then, a piece $(1 \mathrm{~cm} \times 1 \mathrm{~cm})$ was clipped from the leaf, and peeled epidermis to expose mesophyll cells as shown in Fig.2b. Figure $2 \mathrm{c}$ shows an optical micrograph of the pothos cells. It was observed that the size of one cell was 40 to $50 \mu \mathrm{m}$. The distance of tungsten electrodes was adjusted to be the size of 3cells as shown in Fig.2d.

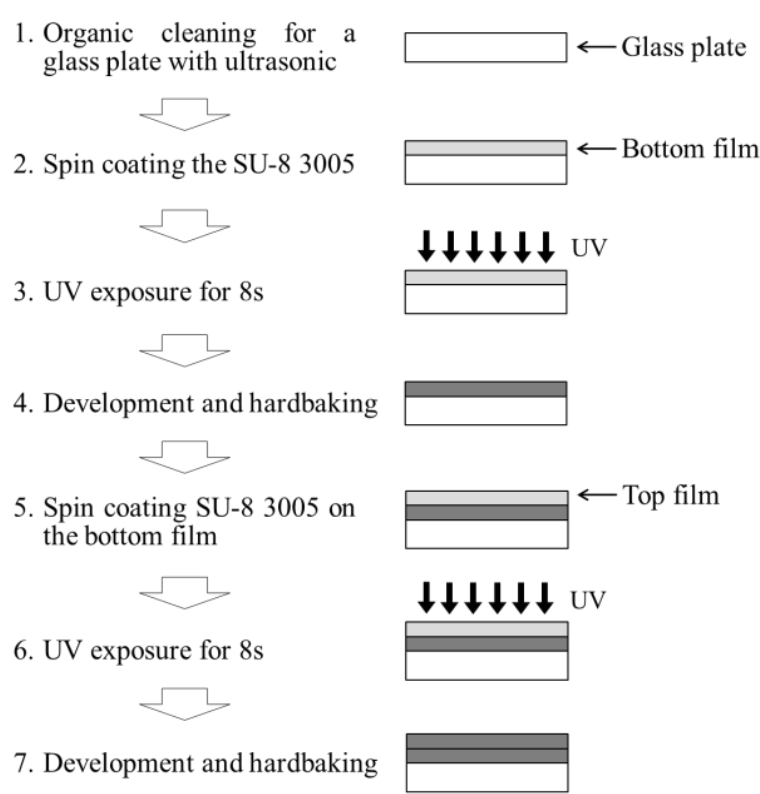

Fig.1. SU-8 film fabrication process (cross-section).

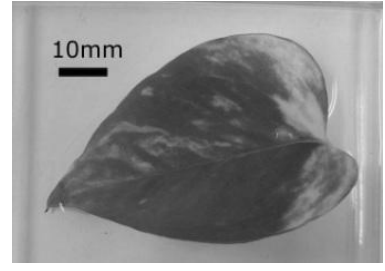

(a) pothos leaf

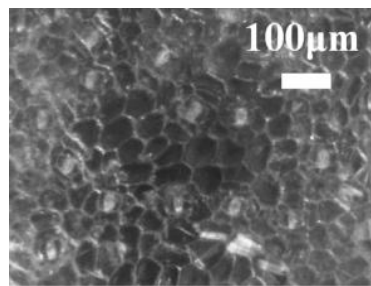

(c) cell of pothos leaf

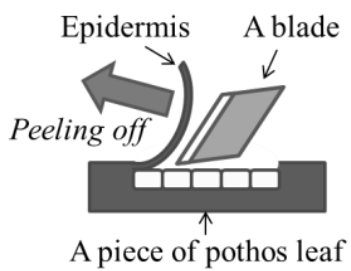

(b) cell exposing method

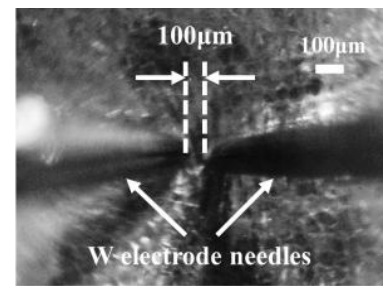

(d) W electrode needle
Fig.2. Plant sample preparation for this experiment and optical microscope images of pothos cells.

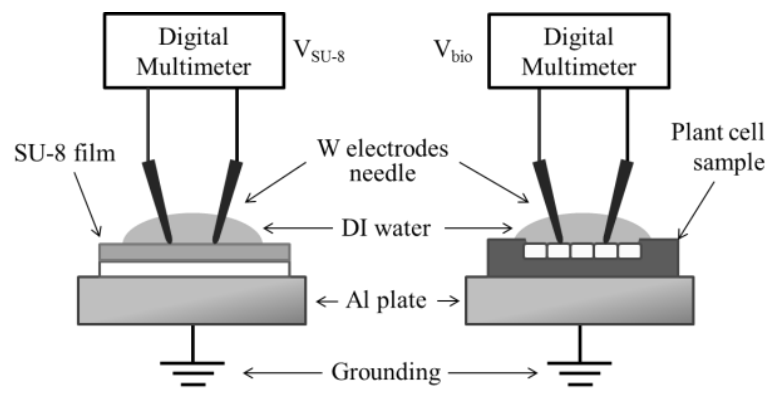
(a) SU-8 film
(b) plant cell

Fig.3. Potential measurement system (cross-section). 


\subsection{Potential measurement system}

A potential measurement system is illustrated in Fig.3. In order to measure surface potential $\mathrm{V}_{\mathrm{SU}-8}$ of a SU-8 film and biopotential $\mathrm{V}_{\text {bio }}$ of pothos cells, we employed a pair of tungsten needle. Curvature radius of the needle was $20 \mu \mathrm{m}$ which was smaller than a pothos cell size around $50 \mu \mathrm{m}$. Terminal of a digital multimeter (KENWOOD, DL-712, the input impedance was larger than $11 \mathrm{M} \Omega$ ) connected to the electrode needles. A liquid drop of deionized water (below $0.06 \times 10^{-4} \mathrm{~S} / \mathrm{cm}$ ) was put on the sample surface. The electrodes were immerged in deionized water for 60s. Then the electrodes were moved slowly to make a contact with the SU-8 film surface and pothos cells. The distances between two tungsten electrodes were set at $409 \mu \mathrm{m}$ for a SU-8 film and $100 \mu \mathrm{m}$ for pothos cells In order to monitor the large variation of in initial stage, the measurement interval was adjusted to be $1 \mathrm{~s}$ until $60 \mathrm{~s}$ of contacting time. After $60 \mathrm{~s}$, the data were recorded in interval 10s. Three different positions, $A, B$ and $C$ for a SU-8 film, $a, b$ and $c$ for pothos cells were selected.

\section{Results}

\subsection{Surface potential $\mathrm{V}_{\mathrm{SU}-8}$ of SU-8 film}

Figure 4 shows the dependency of surface potential $\mathrm{V}_{\mathrm{SU}-8}$ on the contacting time of the SU-8 film. $\mathrm{V}_{\mathrm{SU}-8}$ indicates a maximum value just after making an electrode contact. Then $\mathrm{V}_{\text {SU-8 }}$ exponentially decreases with the contact time. The potential $\mathrm{V}_{\mathrm{SU}-8}$ reaches to the equilibrium value about $+21 \mathrm{mV}$.

\subsection{Biopotential $\mathrm{V}_{\text {bio }}$ of plant cells}

Figure 5 shows the dependency of biopotential $\mathrm{V}_{\text {bio }}$ on the contacting time of pothos cells. We focus on that dynamic change of $V_{\text {bio }}$ generates during the contacting time of electrodes at position $a$ for $6 \mathrm{~s}$ and position $c$ for $32 \mathrm{~s}$. $\mathrm{V}_{\text {bio }}$ also reaches to the equilibrium value in exponential function. The equilibrium value is about $-21 \mathrm{mV}$.

\section{Discussion}

According to comparison $\mathrm{V}_{\mathrm{SU}-8}$ with $\mathrm{V}_{\text {bio }}$, the potential changes after making an electrode contact are different. It is considered that dependency of $\mathrm{V}_{\mathrm{SU}-8}$ on contacting time causes surface charge existence. The surface charge is neutralized on the SU-8 film surface during the measurement, so $\mathrm{V}_{\mathrm{SU}-8}$ decreases as the contacting time. The reason of the surface charge movement would be surface bonding structure. The thermal treatment at the end of SU-8 lithography process

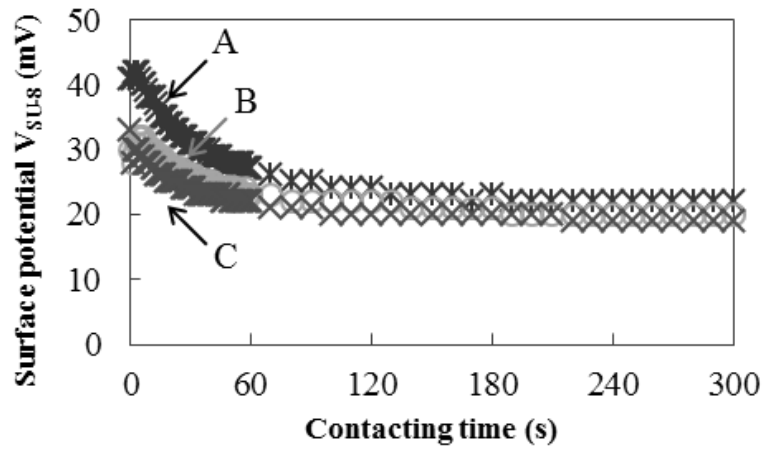

Fig.4. Dependency of surface potential $\mathrm{V}_{\mathrm{SU}-8}$ on contacting time of a SU-8 film.

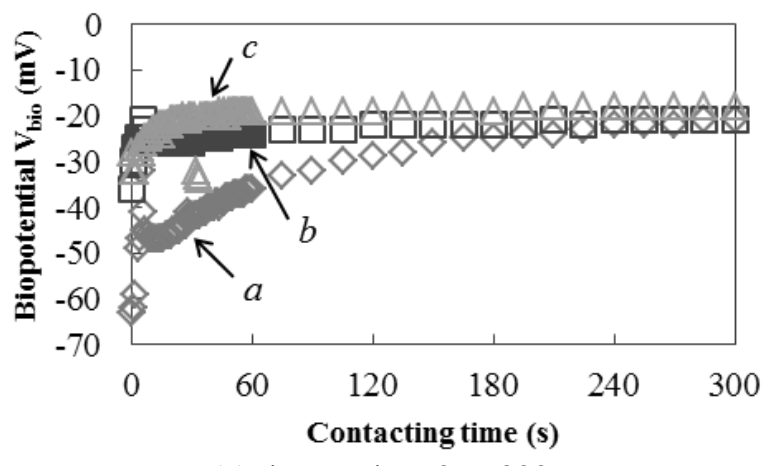

(a) time region: 0 to $300 \mathrm{~s}$

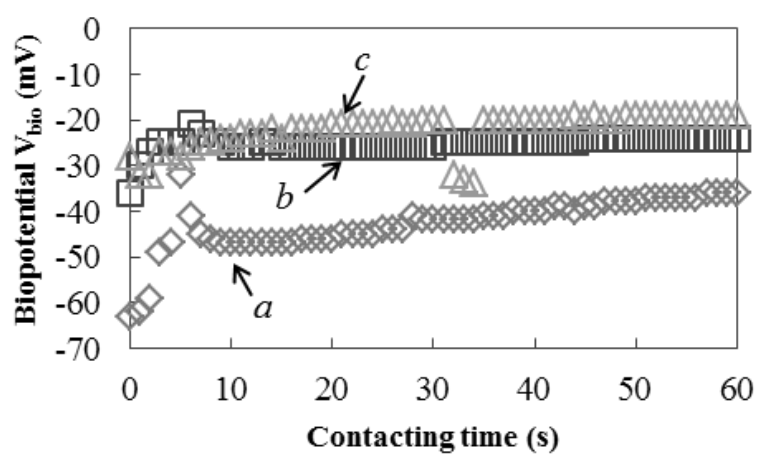

(b)time region: 0 to $60 \mathrm{~s}$

Fig.5. Dependency of biopotential $\mathrm{V}_{\text {bio }}$ on contact time of 3-plant-cell.

occupies an important role in regard with surface stability. In general, main purpose of hardbaking is conducted to volatilize solvent in a films and to enhance adhesion and durability between a film and a substrates. The cross-linking reaction should act to finish epoxy functionalities through this process. Thus, electrical charges in the SU-8 film surface cannot move to electrodes. In regard with equilibrium value, it is possible that zeta potential between the SU-8 film and electrodes should be reflected.

On the other hand, biopotential $\mathrm{V}_{\text {bio }}$ of plant cells is generated by several factors. For example, 
Table 1. Surface potential characteristics of SU-8 film and plant cells.

\begin{tabular}{|c|c|c|c|c|c|c|}
\hline \multirow{2}{*}{$\begin{array}{c}\text { Kinds of potential } \\
\text { Measurement position }\end{array}$} & \multicolumn{3}{|c|}{$\mathbf{V}_{\mathrm{SU}-8}$} & \multicolumn{3}{|c|}{$\mathbf{V}_{\text {bio }}$} \\
\hline & $A$ & $B$ & $C$ & $a$ & $b$ & $c$ \\
\hline Equilibrium value $\quad V_{e q}(\mathrm{mV})$ & +22 & +20 & +19 & -21 & -21 & -18 \\
\hline Range of potential change $\Delta V(\mathrm{mV})$ & 20 & 21 & 14 & 42 & 15 & 10 \\
\hline Time constant $\quad \tau(\mathrm{s})$ & 41.8 & 44.4 & 42.7 & 83.3 & 76.9 & 23.6 \\
\hline
\end{tabular}

ion concentration difference inside and outside of a cell is one major factor $[11,12]$. Therefore, it seems that drastic changes are observed as individualistic biological reaction of living tissues by comparing with a standard equilibrium of a SU-8 film.

In order to evaluate quantitatively potential changes of $\mathrm{V}_{\mathrm{SU}-8}$ and $\mathrm{V}_{\text {bio, }}$, we estimates the time constant by fitting to Eq.1,

$$
V(t)=V_{e q}+\Delta V \exp \left(-\frac{t}{\tau}\right)
$$

where $V_{e q}$ is equilibrium potential values at $\mathrm{t}=300 \mathrm{~s}$ and $\Delta V$ is absolute range of potential change from $\mathrm{t}=0 \mathrm{~s}$ to $300 \mathrm{~s}$. The symbol of $\tau$ denotes the time constant. Equibrium value $V_{e q}$ should reflect zeta potential property. $\Delta V$ and $\tau$ indicate stability of potential change. Table 1 summarized these fitting parameters of $\mathrm{V}_{\mathrm{SU}-8}$ and $\mathrm{V}_{\text {bio }}$. Equilibrium $V_{e q}$ shows same value for each potential. $\Delta V$ of surface potential of a SU-8 film is mostly same among $A$, $B$ and $C$. However, the potential range $\Delta V$ of $\mathrm{V}_{\text {bio }}$ indicates quite different value among the measurement position $a, b$ and $c$. The time constant $\tau$ of $\mathrm{V}_{\mathrm{SU}-8}$ is $41 \mathrm{~s}$ on average from electrodes contact, on the other hand, $\tau$ of $\mathrm{V}_{\text {bio }}$ is not same value at each point. Therefore, the stability of potential change of a SU-8 film can be evaluated quantitatively. We believe that a SU-8 film is capable to use as a standard film of surface potential through quantitative evaluation.

\section{Conclusion}

Surface potential $\mathrm{V}_{\mathrm{SU}-8}$ of the SU-8 and biopotential $\mathrm{V}_{\text {bio }}$ of plant cells are measured and analyzed. $\mathrm{V}_{\mathrm{SU}-8}$ decreases exponentially with the contacting time. A SU-8 film indicates stable film property due to hardbaking procedure. Contrariwise, in regard with $\mathrm{V}_{\text {bio, }}$, dynamic change is observed during the electrodes contact. Dynamic change of $\mathrm{V}_{\text {bio }}$ is considered as individualistic biological reaction of living tissues. A SU-8 film can use as a standard film of surface potential and be applied to a cover material of electrodes surface or a biological implanted device.

\section{Acknowledgements}

The present work was partially supported by Grant-in-Aid for Scientific Research, Grant-in-Aid for Scientific Research (JSPS KAKENHI B: 23360150) and Grant-in-Aid for challenging Exploratory Research (MEXT KAKENHI 23656235).

\section{References}

1. C. M. Hwang, W. Y. Sim, S. H. Lee, A. M. Foudeh, H. Bae, S. H. Lee, A. Khademhosseini, Biofabrication, 2 (2010) 4.

2. M. Chen, P. O. Zamora, P. Som, L. A. Pena, S. Osaki, J. Biomater. Sci. Polymer Edn, 14 (2003) 9.

3. F. Walther, T. Drobek, A. M. Gigler, M. Hennemeyer, M. Kaiser, H. Herberg, T. Shimitsu, G. E. Morfill, R. W. Stark, Surf. Interface Anal., 42 (2010) 12-13.

4. G. Blagoi, S. Keller, A. Johansson, A. Boisen, M. Dufva, Appl. Surf. Sci., 255 (2008) 5.

5. A. del Campo, C. Greiner, J. Micromech. Microeng., 17 (2007) 6.

6. B. P. Chaudhri, F. Ceyssens, P. D. Moor, C. V. Hoof, R. Puers, J. Micromech. Microeng., 20 (2010) 6.

7. G. Voskerician, M. S. Shive, R. S. Shawgo, H. Recum, J. M. Anderson, M. J. Cima, R. Langer, Biomaterials, 24 (2003) 11.

8. B. Bohl, R. Steger, R. Zengerle, P. Koltay, J. Micromech. Microeng., 15 (2005) 6.

9. A. Altuna, L. Menendez de la Prida, E. Bellistri, G. Gabriel, A. Guimerá, J. Berganzo, R. Villa, L. J. Fernández, Biosens. Bioelectron., 37 (2012) 1.

10. SU-8 3000 Data Sheet, (MicroChem Corp.), http://www.microchem.com/Prod-SU83000.htm.

11. T. Ohyabu et al., Bioelectrical potential of plant and communication, Kaibundo, (2009) pp.8-9 (in Japanese).

12. J. Fromm, S. Lautner, Plant, Cell \& Environment, 30 (2007) 3. 